\title{
Perspectiva multissetorial da estrutura produtiva de Rondônia
}

\author{
Multisectoral perspective of Rondônia's productive structure \\ Perspectiva multisectorial de la estructura productiva de Rondônia
}

Recebido: 23/03/2021 | Revisado: 29/03/2021 | Aceito: 30/03/2021 | Publicado: 10/04/2021

\author{
Neima Quele Almeida da Silva \\ ORCID: https://orcid.org/0000-0002-3394-5137 \\ Universidade Federal de Rondônia, Brasil \\ E-mail: neimaquele@unir.br \\ Emanuel Fernando Maia de Souza \\ ORCID: https://orcid.org/0000-0002-5493-2183 \\ Universidade Federal de Rondônia, Brasil \\ E-mail: emanuel@unir.br \\ Carlos André da Silva Muller \\ ORCID: https://orcid.org/0000-0003-3707-6693 \\ Universidade Federal de Rondônia, Brasil \\ E-mail: carlosandre@unir.br
}

\begin{abstract}
Resumo
A Matriz Insumo-Produto é uma ferramenta utilizada para realização de análise dos setores produtivos e suas interrelações, permitindo auxiliar na tomada de decisões econômicas e contribuindo para um melhor planejamento dos setores chave para o desenvolvimento de uma região. De tal modo, buscou-se neste trabalho realizar uma análise multisetorial da economia rondoniense a partir da Matriz Insumo-Produto para a estrutura econômica de 2018. Foram analisados os dados referentes ao Brasil e as vinte e sete unidades da federação. Descobriu-se que os setores que se destacam na economia estadual foram Informação e comunicação, Indústrias de transformação e Alojamento e alimentação nas relações intrarregionais, e os setores de Transporte, armazenagem e correio, Construção e Indústrias extrativas para as relações inter-regionais. Os achados permitem contribuir com o desenvolvimento de políticas que estimulem os setores destacados, amparado pelo crescimento da produção e em consonância com as propostas mais relevantes do desenvolvimento sustentável na Amazônia.
\end{abstract}

Palavras-chave: Sustentável; Multiplicadores; Índices de ligação; Amazônia.

\begin{abstract}
The Input-Product Matrix is a tool used to perform analysis of the productive sectors and their interrelations, helping to make economic decisions, and contributing to a better planning of the key sectors for the development of a region. In this way, this work sought to implement a multisectoral analysis of Rondônia's economy based on the Input-Output Matrix for the 2018 economic structure. Data from Brazil and the twenty-seven units of the federation were analyzed. The sectors that stood out in the state economy were found to be Information and communication, Manufacturing, and Accommodation and food in intra-regional relations, and the sectors of Transport, storage and mail, Construction, and Extractive industries for interregional relations. The findings make it possible to contribute to the development of policies that stimulate the highlighted sectors, supported by the growth of production and in line with the most relevant proposals for sustainable development in the Amazon.
\end{abstract}

Keywords: Sustainable; Multipliers; Forward and backward linkages; Amazon.

\section{Resumen}

La Matriz Insumo-Producto es una herramienta que se utiliza para realizar análisis de los sectores productivos y sus interrelaciones, ayudando a la toma de decisiones económicas y contribuyendo a una mejor planificación de los sectores clave para el desarrollo de una región. De esta manera, este trabajo buscó realizar un análisis multisectorial de la economía en Rondônia a partir de la Matriz Insumo-Producto para la estructura económica de 2018. Se analizaron datos de Brasil y las veintisiete unidades de la federación. Los sectores que se destacaron en la economía estatal fueron Información y comunicación, Fabricación y Alojamiento y alimentación en las relaciones intrarregionales, y los sectores de Transporte, almacenamiento y correo, Construcción e Industrias extractivas para las relaciones interregionales. Los hallazgos permiten contribuir al desarrollo de políticas que estimulen los sectores destacados, apoyados en el crecimiento de la producción y en línea con las propuestas más relevantes para el desarrollo sostenible en la Amazonía.

Palabras clave: Sostenible; Multiplicadores, Índices de vinculación; Amazonía. 


\section{Introdução}

Os modelos multisetoriais de mensuração econômica, em especial a Matriz Insumo-Produto (MIP), ao longo das últimas décadas têm se mostrado de muita utilidade na compreensão das diversas estruturas produtivas, permitindo, por exemplo, a identificação dos setores-chaves de uma economia (Isard, 1951; Finamore, 2018), a realização de análise de comércio internacional (Chen, et al., 2018), análise de crises econômicas (Günther, Kristalova, \& Ludwig, 2019), pressão sobre determinados recursos naturais (Wang, Fath, \& Chen, 2019), ou impactos ambientais (Lenzen, 1998; Lenzen, Murray, Korte, \& Dey, 2003; Wood, 2009). Com a matriz é possível identificar, além dos setores-chave no encadeamento da produção, o emprego e as exportações líquidas, permitindo efetuar simulações setoriais de impacto na produção e no emprego (Souza, 1997). Atribui-se que uma análise multissetorial, ou inter-regional, tal como a MIP, é relevante para uma melhor compreensão econômica da região possibilitando uma fonte científica segura para futuras decisões de políticas públicas.

Neste sentido, poucos são os estudos nessa área para os estados da Amazônia, não tendo sido encontrado nenhum trabalho de órgãos oficiais na elaboração da MIP para o Estado de Rondônia. À propósito, o Instituto Brasileiro de Geografia e Estatística (IBGE) disponibiliza a matriz nacional e apenas alguns estados possuem núcleos de pesquisa para sua elaboração. Essa prática poderia levar a disponibilização de uma ferramenta de análise e tomada de decisões para o desenvolvimento econômico e social mais adequada as realidades existentes dos estados da Amazônia. Visto que, Rondônia tem sido laboratório de políticas econômicas, de colonização e da expansão da fronteira agrícola brasileira, resultando em uma imensa transformação da paisagem regional, alterando significativamente o uso do solo e sendo uma das regiões mais desmatadas da Amazônia (Fearnside, 1997; Fearnside, 2005; Becker, 2005). A exemplo, em 2016, o desmatamento na Amazônia chegou a $7.893 \mathrm{~km}^{2}$ e Rondônia contribuiu com 17\% (1.376 km²), e em 2019, o desmatamento na Amazônia foi de $9.762 \mathrm{~km}^{2}$ e Rondônia teve uma contribuição de 13\% (1.421 km²) (INPE, 2019), sendo ainda um dos estados protagonistas da crise dos incêndios de 2019 (Lizundia-Loiola, Pettinari, \& Chuvieco, 2020; Silveira, et al., 2020). Estudos de simulação do desmatamento em Rondônia indicam que o estado poderá ter, em 2050, até 47\% do seu território ocupado por áreas de florestas convertido em áreas desflorestadas, incluindo as áreas protegidas (Piontekowski, et al., 2019).

Assim, com a finalidade de preencher esta lacuna, esta pesquisa buscou realizar uma análise multisetorial de mensuração da participação dos setores econômicos, identificando os setores chave para o desenvolvimento regional, a participação de cada setor e suas interdependências, utilizando-se dos multiplicadores de produção e índices de ligação. Para isso, optou-se pela análise de insumo-produto, o que leva à construção da Matriz de Insumo-Produto - MIP para o Estado de Rondônia em sua forma regionalizada, um sistema inter-regional abrangendo as vinte e sete unidades da federação do país. Conforme identificado, a MIP-RO permite fazer uma análise de uma economia regional, uma vez que integra os níveis macro e setorial, levando a interações entre os diversos setores da economia (Richardson, 1978).

\section{Referencial teórico}

\subsection{Definição de desenvolvimento}

O conceito de desenvolvimento tem recebido ampla contribuição, principalmente a partir de meados do século XX, com diversas definições tais como, desenvolvimento econômico (Souza, 1990), ecodesenvolvimento (Mellos, 1988), desenvolvimento sustentável (WCED, 1987), desenvolvimento rural (Seers, 1969; Calatrava-Requena, 2016), desenvolvimento regional (Souza, 2005), entre outras. A discussão ampliou-se também em relação as suas dimensões, por exemplo, social, cultural, ecológica, ambiental, territorial, econômica, política (nacional e internacional) (Sachs, 2008).

Desenvolvimento pode ainda ser considerado como sinônimo de crescimento, baseado em modelos que enfatizam acumulação de capital, tendo como um dos seus indicadores a renda per capita (Souza, 1999), muito embora, parece ser consenso que a definição vai além de crescimento econômico, pressupondo uma melhoria na vida das pessoas, com base em 
um modelo ou não, ou ainda, pode referir-se ao atendimento às necessidades básicas dos seres humanos, dependendo do arcabouço teórico elegido (Seers, 1969). É perceptível dentro do mainstream econômico a incorporação do desenvolvimento aos modelos macroeconômicos, uma vez que passaram a adotar as variáveis ambiental, poupança intertemporal, à medida que a discussão ganhou notoriedade no século XX. O desenvolvimento pode ainda, ser algo mais amplo, indicando também melhoria na qualidade de vida, permitindo acesso à educação e cuidados com a saúde, oportunidades de emprego, disponibilidade de ar limpo e água potável, por exemplo (Soubbotina \& Sheram, 2000; Jackson, 2009).

A propósito do termo Desenvolvimento sustentável, temática em evidência nas últimas décadas, ainda em evolução, é um conceito que destaca as questões ambientais, e que passam também a ser relacionadas com outras questões como desigualdade de renda. Ganhou notoriedade nos anos de 1980, após a publicação do Relatório Brundtland, resultado de anos de discussão, quando se deu o entendimento de desenvolvimento sustentável como o desenvolvimento que garante a satisfação das necessidades do presente sem comprometer a satisfação das necessidades das futuras gerações (WCED, 1987). A discussão foi iniciada na primeira Conferência Mundial sobre o Homem e o Meio Ambiente (1972), em Estocolmo, além de outras reuniões em diferentes partes do mundo tratando de assuntos como crescimento econômico e meio ambiente, originada no relatório Os Limites do crescimento (Meadows, Meadows, Randers, \& Behrens III, 1972) cujo escopo do texto era catastrófico. O conteúdo apresentado no Relatório Brundtland era suficientemente abrangente para manter debates internacionais que alcançaram as décadas seguintes e a realização de novas edições da Conferência das Nações Unidas sobre o Meio Ambiente e o Desenvolvimento, tais a ECO-92, em 1992, e a Rio+20, em 2012, ambas ocorridas no Brasil.

Permeando o debate mais abrangente, a discussão regional segue sendo teorizada por especialistas que colocam em evidência as relações internas ao desenvolvimento, como o papel do Estado e das próprias comunidades no estímulo a este desenvolvimento. Por um lado, a constatação de que o Estado, como promotor e agente alocativo do mercado, foi insuficiente na promoção do desenvolvimento por meio dos modelos tradicionais (MULS, 2008). Por outro, a necessidade de políticas de desenvolvimento pensadas de forma a combinar as instituições econômicas, sociais, culturais e políticas, em um modelo de desenvolvimento de baixo para cima (Amaral Filho, 1996). Estas mesmas instituições, diferentes para cada país, região ou localidade, leva a uma percepção de não comparabilidade entre os caminhos, rotas ou formas de desenvolvimento, já que se moldam de forma única (Arend, Cario, \& Enderle, 2012).

Assim, o desenvolvimento endógeno, como aquele que está associado à valorização dos recursos locais se coloca como chave para o desenvolvimento nas regiões mais afastadas dos grandes centros urbanos, tal o que ocorre com a maioria das cidades da região amazônica.

\subsection{Caracterização do Estado de Rondônia}

O estado de Rondônia localiza-se na porção sudoeste da bacia Amazônia, e compõe a Região Norte do Brasil. Esta região é composta por sete estados, sendo a maior região do país, com aproximadamente $45 \%$ da área total e a segunda região menos habitada. Resultado principalmente de políticas de expansão da fronteira agrícola, que levou a considerável desflorestamento da região, Rondônia tem buscado uma política de desenvolvimento que se baseia no Zoneamento EcológicoEconômico (ZEE) visando um "desenvolvimento sustentável, reconhecendo os atributos bióticos, abióticos, estéticos e culturais como ativo para o desenvolvimento regional” (Rondônia, 2015). No entanto, o Estado ainda apresenta altos índices de desmatamento oscilando entre o terceiro e quarto maior desmatador da região Norte, contribuindo com altas taxas de degradação. Um dos principais motivos para isso é a conversão do solo para uso agrícola e pastagem ou retirada de madeira, uma característica de toda a região (Fearnside, 2005).

De acordo com informações demográficas, Rondônia possui uma população estimada em 1,77 milhão de pessoas, o que representa $10 \%$ dos habitantes da Região Norte e cerca de $0,9 \%$ da população nacional (IBGE, 2019). Com o $19^{\circ}$ maior 
Índice de Desenvolvimento Humano (IDH) do Brasil, 0,725, uma medida comparativa de riqueza, alfabetização, educação, esperança de vida e natalidade, Rondônia encontra-se acima da média e com nenhum município apresentando índice muito baixo. A capital, Porto Velho, apresenta um IDH-M (referente à município) de 0,736 , considerado alto e o município de Vale do Anari apresenta um índice de 0,584, considerado baixo (IBGE, 2010).

O Estado é composto por 52 municípios, possui o $3^{\circ}$ maior Produto Interno Bruto (PIB) da região e $22^{\circ}$ do país (IBGE, 2018). Além disso, a economia do Estado possui uma evolução forte tendo seu PIB per capita nominal variado de R\$ $5.147,40$ (2002) para $\mathrm{R} \$ 25.554,31$ (2018), indo da $16^{\mathrm{a}}$ para a $12^{\mathrm{a}}$ posição, nos períodos citados, em termos de participação na razão PIB per capita e PIB. Para o mesmo período se observou um crescimento do PIB per capita brasileiro de R \$ 8.440,27 (2002) para $\mathrm{R} \$ 33.593,82$ (2018) (IBGE, 2018).

Em 2018, o PIB de Rondônia chegou a pouco mais de 40 bilhões com maior participação da Administração Pública (28\%), seguida pelo setor de Comércio (13\%), Atividade imobiliárias (11\%) e Pecuária (10\%) (Tabela 1). Todavia, em relação ao PIB do Brasil, R\$ 7 trilhões, Rondônia possui uma contribuição de 0,006\% (IBGE, 2018). É importante destacar que o comércio praticamente se equipara a produção da atividade agropecuária e a Administração pública aproxima-se do total produzido pelos setores agropecuário e industrial.

Tabela 1 - Valor Adicionado Bruto (VAB) de Rondônia, à preços correntes, em R\$ milhão, nos anos de 2014 a 2018.

\begin{tabular}{|c|c|c|c|c|c|c|c|c|c|c|}
\hline & 2014 & $\%$ & 2015 & $\%$ & 2016 & $\%$ & 2017 & $\%$ & 2018 & $\%$ \\
\hline Agropecuária & 3.868 & 13 & 4.353 & 13 & 4.915 & 14 & 5.877 & 15 & 5.732 & 14 \\
\hline Agricultura, inclusive apoio à agricultura e a pós-colheita & 711 & 2,34 & 694 & 2,13 & 938 & 2,65 & 1.305 & 3,32 & 1.126 & 2,8 \\
\hline Pecuária, inclusive apoio à Pecuária & 2.880 & 9,48 & 3.285 & 10,09 & 3.571 & 10,09 & 3.889 & 9,9 & 3.949 & 9,81 \\
\hline Produção florestal, pesca e aquicultura & 276 & 0,91 & 374 & 1,15 & 406 & 1,15 & 682 & 1,74 & 657 & 1,63 \\
\hline Indústrias & 5.450 & 18 & 6.039 & 19 & 6.573 & 19 & 8.194 & 21 & 7.063 & 18 \\
\hline Indústrias extrativas & 83 & 0,27 & 93 & 0,29 & 32 & 0,09 & 103 & 0,26 & 112 & 0,28 \\
\hline Indústrias de transformação & 1.735 & 5,71 & 1.889 & 5,8 & 2.393 & 6,76 & 2.056 & 5,23 & 2.217 & 5,51 \\
\hline $\begin{array}{l}\text { Eletricidade e gás, água, esgoto, atividades de gestão de resíduos e } \\
\text { descontaminação }\end{array}$ & 563 & 1,85 & 1.480 & 4,54 & 2.434 & 6,88 & 4.458 & 11,35 & 3.378 & 8,39 \\
\hline Construção & 3.069 & 10,1 & 2.577 & 7,91 & 1.713 & 4,84 & 1.576 & 4,01 & 1.356 & 3,37 \\
\hline Serviços & 21.059 & 69 & 22.181 & 68 & 23.898 & 68 & 25.210 & 64 & 27.465 & 68 \\
\hline Comércio e reparação de veículos automotores e motocicletas & 4.435 & 14,6 & 4.571 & 14,03 & 4.684 & 13,24 & 4.861 & 12,37 & 5.365 & 13,33 \\
\hline Transporte, armazenagem e correio & 836 & 2,75 & 877 & 2,69 & 913 & 2,58 & 870 & 2,22 & 1.061 & 2,63 \\
\hline Alojamento e alimentação & 450 & 1,48 & 513 & 1,57 & 508 & 1,44 & 596 & 1,52 & 719 & 1,79 \\
\hline Informação e comunicação & 353 & 1,16 & 383 & 1,18 & 339 & 0,96 & 385 & 0,98 & 361 & 0,9 \\
\hline Atividades financeiras, de seguros e serviços relacionados & 799 & 2,63 & 946 & 2,9 & 1.086 & 3,07 & 1.167 & 2,97 & 1.222 & 3,04 \\
\hline Atividades imobiliárias & 2.893 & 9,52 & 3.252 & 9,98 & 3.538 & 10 & 3.705 & 9,43 & 4.391 & 10,91 \\
\hline $\begin{array}{l}\text { Atividades profissionais, científicas e técnicas, administrativas e serviços } \\
\text { complementares }\end{array}$ & 1.201 & 3,95 & 1.027 & 3,15 & 1.098 & 3,1 & 1.109 & 2,82 & 1.111 & 2,76 \\
\hline Administração, defesa, educação e saúde públicas e seguridade social & 8.537 & 28,1 & 9.058 & 27,81 & 9.893 & 27,96 & 10.760 & 27,39 & 11.382 & 28,27 \\
\hline Educação e saúde privadas & 774 & 2,55 & 839 & 2,57 & 1.035 & 2,93 & 947 & 2,41 & 1.010 & 2,51 \\
\hline Artes, cultura, esporte e recreação e outras atividades de serviços & 469 & 1,54 & 370 & 1,14 & 396 & 1,12 & 334 & 0,85 & 402 & 1 \\
\hline Serviços domésticos & 313 & 1,03 & 345 & 1,06 & 409 & 1,15 & 477 & 1,21 & 440 & 1,09 \\
\hline TOTAL & 30.376 & 100 & 32.574 & 100 & 35.385 & 100 & 39.281 & 100 & 40.260 & 100 \\
\hline
\end{tabular}

Fonte: IBGE, Contas Regionais (2010-2018).

\section{Metodologia}

A presente pesquisa faz um estudo quantitativo da estrutura econômica de Rondônia, uma vez que apresenta dados que podem ser quantificados, mensurados e encontram-se organizados e tabulados, de forma que pode ser feito o uso de 
equações e/ou fórmulas matemáticas (Martins \& Theóphilo, 2009; Pereira, Shitsuka, Parreira, \& Shitsuka, 2018). No entanto, busca interpretar os resultados encontrados de forma a contribuir para a realidade social, o que caracteriza também a pesquisa, complementarmente, como qualitativa. Características avaliativas não são, portanto, impeditivas de uma análise qualitativa, mesmo porque seria descabido considerar uma pesquisa exclusivamente como quantitativa ou qualitativa (Martins \& Theóphilo, 2009).

A unidade de análise da pesquisa é o Estado de Rondônia, visto sob uma perspectiva de desenvolvimento regional. Para isso foi realizada uma análise multisetorial de mensuração da participação dos setores econômicos. Optou-se pela análise de insumo-produto, o que leva à construção da Matriz de Insumo-Produto - MIP para o Estado de Rondônia. A MIP-RO permite fazer uma análise de desenvolvimento econômico regional, uma vez que integra os níveis macro e setorial, permitindo observar as interações entre os diversos setores da economia.

A MIP é geralmente construída a partir de dados empíricos observados para uma região específica. Concentra-se na atividade produtiva de um grupo de indústrias que produz bens e serviços e consome bens e serviços de outras indústrias (Muller \& Blair, 2009). No entanto, quando se trata de análise regional há ausência de dados, implicando na necessidade de combinação de métodos censitários com métodos não-censitários, em particular, optou-se pela utilização das Tabelas de Recursos e Usos nacionais e estaduais, com base nos dados das Contas Nacionais e Contas Regionais.

O modelo de insumo-produto pode ser derivado a partir das identidades contábeis que mostram como a produção de um determinado setor $i$ é utilizada pelos demais e pela demanda final " $Y$ ", descrevendo a distribuição da produção de uma indústria através da economia por meio de equações lineares (Haddad, 1976; Muller \& Blair, 2009).

$\mathrm{O}$ modelo pode ser representado pela equação $X=(I-A)^{-1} Y$, onde $\mathrm{X}$ é o valor bruto de produção, A é a matriz de coeficientes técnicos, $I$ representa a matriz identidade, $(I-A)^{-1}$ é uma matriz inversa chamada de matriz de Leontief. A matriz de Leontief, ou matriz de coeficientes técnicos, permite verificar para cada setor qual o volume de produção necessário para atender a uma determinada configuração de demanda (Paulani \& Braga, 2007).

\subsection{Construção da Matriz Insumo-Produto regionalizada}

A MIP rondoniense foi desenvolvida com base nas Tabelas de Recursos e Usos nacionais, referente ao ano de 2018. Para a construção do sistema inter-regional foram elaboradas as Tabelas de Recursos e Usos - TRUs para os estados, que oferecem as tabelas de produção e consumo intermediário (IBGE, 2018). Para tanto, foram utilizados os dados constantes nas Contas Regionais disponibilizadas pelo IBGE, referentes ao ano de 2018, para cada uma das vinte e sete unidades da federação.

Primeiramente foi necessário compatibilizar os dados referentes aos setores do Cadastro Nacional de Atividades Econômicas (CNAE) das atividades estaduais com os setores das Tabelas de Recursos e Usos nacionais, uma vez terem sido utilizadas como parâmetro. Isso significa que as TRUs nacionais foram compatibilizadas para as mesmas categorias estaduais. Como resultado foram obtidas TRUs com 18 setores econômicos, somando 127 produtos, a nível nacional (IBGE, 2018).

Foram estimadas as Matrizes de Produção estaduais, as matrizes de exportações e importações, as matrizes de demanda final (além das exportações, contém as matrizes de consumo do governo, consumo das famílias, consumo das Instituições Sem Fim Lucrativo ao Serviço das Famílias - ISFLSF, formação bruta de capital fixo - FBKF e variação de estoques), consumo intermediário, inter-regional, consumo intermediário intrarregional, valor adicionado bruto, impostos indiretos líquidos e número de pessoas ocupadas. Todos os valores foram desagregados para as vinte e sete unidades da federação e dezoito setores (Guilhoto \& Sesso-Filho, 2005; Guilhoto, Gonçalves Junior, Visentin, Imori, \& Ussami, 2017; Muller \& Blair, 2009). Sua apresentação, à título de resultados, foi feita a partir do sistema Rondônia e Resto do Brasil. 
À propósito de ilustração, apresenta-se a seguir um modelo básico de estrutura para duas regiões ( $\mathrm{r}$ e s), a primeira com três setores e a segunda com dois setores, resultando em uma matriz quadrada 5x5 (Tabela 2).

Tabela 2 - Fluxo de bens intermediários do sistema inter-regional.

\begin{tabular}{|c|c|c|c|c|c|c|}
\hline & & \multicolumn{5}{|c|}{ Compradores } \\
\hline & & \multicolumn{3}{|c|}{ Região $\mathbf{r}$} & \multicolumn{2}{|c|}{ Região s } \\
\hline \multicolumn{2}{|c|}{ Vendedores } & 1 & 2 & 3 & 1 & 2 \\
\hline \multirow{3}{*}{ Região r } & 1 & $z_{11}^{Y Y}$ & $z_{12}^{r y}$ & $z_{1 a}^{Y Y}$ & $z_{11}^{r s}$ & $z_{12}^{r g}$ \\
\hline & 2 & $z_{21}^{r Y}$ & $z_{22}^{r y}$ & $z_{2 a}^{r y}$ & $z_{21}^{r s}$ & $z_{22}^{r s}$ \\
\hline & 3 & $z_{31}^{r T}$ & $z_{32}^{r y}$ & $z_{a \mathrm{a}}^{r T}$ & $z_{31}^{r s}$ & $z_{12}^{r s}$ \\
\hline \multirow{2}{*}{ Região s } & 1 & $\mathrm{z}_{11}^{S r}$ & $z_{12}^{S Y}$ & $\mathrm{z}_{13}^{s y}$ & $z_{11}^{S S}$ & $z_{12}^{s g}$ \\
\hline & 2 & $z_{21}^{g r}$ & $z_{22}^{E F}$ & $\mathrm{z}_{2 \mathrm{a}}^{\mathbb{E r}}$ & $z_{21}^{S E}$ & $z_{22}^{58}$ \\
\hline
\end{tabular}

Fonte: Muller e Blair (2009, p.77).

São apresentadas as matrizes de fluxos intrarregional $\left(\mathrm{Z}^{\mathrm{rr}} \mathrm{e} \mathrm{Z}^{\mathrm{ss}}\right)$, bem como as matrizes de fluxos inter-regionais $\left(\mathrm{Z}^{\mathrm{sr}} \mathrm{e}\right.$ $\mathrm{Z}^{\mathrm{rs}}$ ), onde $\mathrm{Z}^{\text {sr }}$ e $\mathrm{Z}^{\mathrm{rs}}$ apresentam o efeito transbordamento (Tabela 2). Os dados também podem ser representados como:

$$
Z=\left|\begin{array}{ll}
Z^{\mathrm{rr}} & Z^{\mathrm{rs}} \\
Z^{\mathrm{sr}} & Z^{\mathrm{ss}}
\end{array}\right|
$$

Para o exemplo com duas regiões e tomando a primeira linha (Tabela 2), o sistema de equações lineares fica expresso como:

$$
X_{1}^{r}=z_{11}^{r r}+z_{12}^{r r}+z_{13}^{r r}+z_{11}^{r s}+z_{12}^{r s}+f_{1}^{r}
$$

Onde:

$X_{i}^{r}$ representa a produção total do setor $i$, da região r.

$z_{i j}^{r s}$ representa as vendas do setor $i$ da região $r$, para o setor $j$ da região $s$.

$f_{i}^{r}$ representa as vendas do setor $i$ para a demanda final da respecitiva região e setor.

A matriz $\left(A^{r r}\right)$ de coeficientes técnicos expressa, segundo o modelo geral de insumo-produto, a estrutura econômica identificando a proporção consumida por cada setor intermediário, da seguinte forma:

$$
A^{r r}=Z^{r r} \cdot\left(\widehat{X}^{r}\right)^{-1}
$$

Onde $\left(\widehat{X}^{r}\right)^{-1}$ é inversa da matriz diagonalizada da produção total do setor $r$ e cada elemento da matriz de coeficientes técnicos é definido por:

$$
a_{i j}^{r r}=z_{i j}^{r r} / X_{j}^{r}
$$

Rearranjando a fórmula tem-se:

$$
z_{i j}^{r r}=a_{i j}^{r r} \cdot X_{j}^{r}
$$


Realizando a substituição na primeira equação e estendendo para as demais linhas da matriz, obtém-se:

$$
\begin{array}{lllll}
X_{1}^{r}=a_{11}^{r r} \cdot X_{1}^{r}+a_{12}^{r r} \cdot X_{2}^{r}+a_{13}^{r r} \cdot X_{3}^{r} & +a_{11}^{r s} \cdot X_{1}^{s}+a_{12}^{r s} \cdot X_{2}^{s} & + & f_{1}^{r} \\
X_{2}^{r}=a_{21}^{r r} \cdot X_{1}^{r}+a_{22}^{r r} \cdot X_{2}^{r}+a_{23}^{r r} \cdot X_{3}^{r} & +a_{21}^{r s} \cdot X_{1}^{s}+a_{22}^{r s} \cdot X_{2}^{s} & + & f_{2}^{r} \\
X_{3}^{r}=a_{31}^{r r} \cdot X_{1}^{r}+a_{32}^{r r} \cdot X_{2}^{r}+a_{33}^{r r} \cdot X_{3}^{r} & +a_{31}^{r s} \cdot X_{1}^{s}+a_{32}^{r s} \cdot X_{2}^{s} & + & f_{3}^{r} \\
X_{1}^{s}=a_{11}^{s r} \cdot X_{1}^{r}+a_{12}^{s r} \cdot X_{2}^{r}+a_{13}^{s r} \cdot X_{3}^{r} & +a_{11}^{s s} \cdot X_{1}^{s}+a_{12}^{s s} \cdot X_{2}^{s} & + & f_{1}^{s} \\
X_{2}^{s}=a_{21}^{s r} \cdot X_{1}^{r}+a_{22}^{s r} \cdot X_{2}^{r}+a_{23}^{s r} \cdot X_{3}^{r} & +a_{11}^{s s} \cdot X_{1}^{s}+a_{12}^{s s} \cdot X_{2}^{s} & + & f_{2}^{s}
\end{array}
$$

Os impactos nas mudanças ocorridas na estrutura econômica a partir de alterações em elementos demanda final, podem ser representados conforme segue:

$$
X^{r}=\left(I-A^{r r}\right)^{-1} \cdot f^{r}
$$

O que expressa o modelo de Leontief a partir de sua matriz inversa.

Para obtenção das matrizes nacionais e estaduais de produção foram estimados os coeficientes nacionais de produção $\left(C P^{N}\right)$ a partir da matriz nacional de produção $\left(M P^{N}\right)$ (Guilhoto, Gonçalves Junior, Visentin, Imori, \& Ussami, 2017):

$$
C P^{N}=M P^{N} \cdot\left(\hat{X}^{N}\right)^{-1}
$$

Onde $\left(\hat{X}^{N}\right)^{-1}$ representa a inversa do vetor diagonalizado de produção nacional.

As matrizes de produção estaduais (MP ${ }^{\mathrm{UF}}$ ) foram obtidas a partir da seguinte equação:

$$
M P^{U F}=C P^{N} \cdot\left(\hat{X}^{U F}\right)
$$

Onde $\left(\hat{X}^{U F}\right)$ representa o vetor diagonalizado de produção estadual para cada UF.

Para estimação das matrizes de importações, foram calculados os coeficientes nacionais de importações $\left(\operatorname{Cimp}^{N}\right)$ e em seguida foram calculadas as matrizes de importações estaduais $\left(M_{i m p}^{U F}\right)$ :

$$
\operatorname{Mimp}^{U F}=\operatorname{Cimp}^{N} \cdot\left(\widehat{\operatorname{Im}}{ }^{U F}\right)
$$

Onde $\left(\widehat{\operatorname{Imp}}^{U F}\right)$ representa o vetor diagonalizado de importação estadual para cada UF. Em seguida, são feitos os devidos ajustes pelo método RAS.

Os elementos do valor adicionado e os impostos indiretos líquidos foram estimados seguindo o mesmo processo de definição de estimadores da etapa anterior.

Para estimação dos elementos do consumo intermediário foi utilizado o método de quociente locacional interindustrial (Cross-Industry Quotient, CIQ), de forma que as relações de consumo intrarregionais sejam obtidas, apresentando a tendência importadora dos setores de cada estado (Muller \& Blair, 2009):

$$
C I Q_{i j}^{U F}=\left(\frac{x_{i}^{U F} / x_{i}^{N}}{x_{j}^{U F} / x_{j}^{N}}\right)
$$

Onde, $x_{i}^{U F}$ é a produção total do produto para cada UF;

$x_{i}^{N}$ é a produção total nacional do produto;

$x_{j}^{U F}$ é a produção total regional do setor, para cada UF;

$x_{j}^{N}$ é a produção total nacional do setor. 
O resultado é um índice que informa a necessidade de importação pelo setor, que não sendo atendida pela produção interna será suprida pela importação dos demais estados. ${ }^{1}$

Para a estimação das matrizes inter-regionais foi utilizada a seguinte equação (Guilhoto, Gonçalves Junior, Visentin, Imori, \& Ussami, 2017):

$$
C I I^{U F}=\text { CICI }^{U F} \cdot \widehat{C I T}^{U F}
$$

Onde, $C I I^{U F}$ é o consumo intermediário inter-regional estadual;

$C I C I^{U F}$ é o coeficiente de consumo intermediário inter-regional estadual;

$\widehat{C I T}^{U F}$ é o vetor diagonalizado do consumo intermediário total da UF.

Em seguida foram estimadas as matrizes de demanda final. Para obtenção do Consumo das Famílias e FBCF, foi utilizada a técnica do quociente locacional simples (Muller \& Blair, 2009).

\subsection{Multiplicadores e Índices}

A partir da MIP é possível a utilização de alguns indicadores que permitem a análise para uso em gestão e planejamento, por exemplo. Dentre eles, os coeficientes técnicos de insumo-produto (que apresenta um dos núcleos centrais do modelo de Leontief), a matriz inversa de Leontief e, a partir dela, os indicadores de impactos diretos e indiretos.

Os multiplicadores de impacto estimam as repercussões que mudanças no nível de demanda têm sobre a renda total, produção ou emprego e são obtidos por meio da matriz inversa de Leontief (Richardson, 1978). Indicam o impacto de uma variação na demanda final sobre o valor bruto de produção dos setores (Haddad, 1976). No entanto, não permitem identificar em que setores as mudanças se iniciam (Richardson, 1978).

O multiplicador de produção ou multiplicador setorial apresenta a soma das necessidades diretas e indiretas de todos os setores para fornecer um determinado valor monetário adicional de produto do setor $i$ à demanda final total e é obtido somando-se a coluna do setor $i$ na matriz inversa de Leontief (Richardson, 1978). Os multiplicadores parciais mostram o efeito sobre cada setor. É dado por cada célula, representando o impacto do setor $i$ no setor $j$. Cada coluna da matriz indica o efeito do aumento de R \$1 na demanda, em relação a determinado setor, sobre a quantidade de insumos necessários para a produção do setor e sobre o Valor Bruto de Produção setorial e total.

Os índices de ligação demonstram o conceito de setor-chave em uma economia (Muller \& Blair, 2009). O índice de ligação para trás (ILT) representa até que ponto um setor demanda insumos em comparação com os demais. Quando o índice é acima de 1, tem-se que o setor é altamente dependente dos demais. É obtido calculando a média de uma coluna típica e dividindo pela média de todos os elementos da matriz. Enquanto o índice de ligação para frente (ILF) representa até que ponto um setor tem seus insumos demandados por outros setores. Quando o índice é acima de 1, indica um setor que tem sua produção altamente demandada pelos demais. É obtido calculando a média de uma linha típica e dividindo pela média de todos os elementos da matriz.

\section{Resultados}

\subsection{Participação setorial na economia de Rondônia}

A indústria possui forte relação de interdependência setorial, uma vez que representa a maior fração do consumo intermediário e da demanda final (Figura 1). Porém, Serviços detém a maior participação na demanda final, no entanto, muito próximo da participação da Indústria.

${ }^{1}$ Mais informações sobre as técnicas locacionais podem ser encontradas em Muller e Blair, 2009, p.349, que exploraram algumas formas de quocientes e suas aplicações. 
Figura 1 - Participação percentual econômica setorial na demanda total, no estado de Rondônia, 2018.

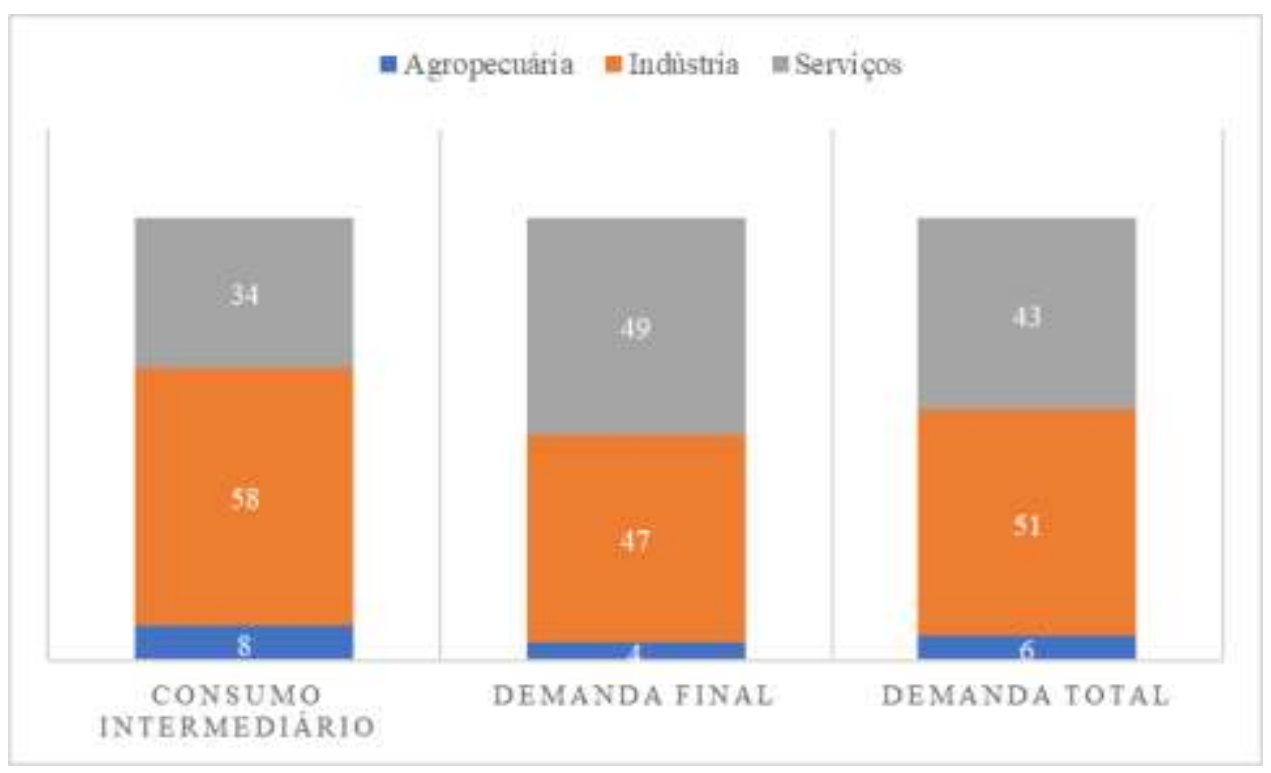

Fonte: Autores, com dados da pesquisa.

A indústria, além de apresentar uma das maiores contribuições ao valor bruto de produção, detém a maior participação das atividades econômicas intermediárias por meio da Indústria de transformação e Eletricidade e gás, água, esgoto, atividades de gestão de resíduos e descontaminação com $56 \%$ e $31 \%$, respectivamente, no setor (Tabela 3).

Tabela 3 - Participação das atividades econômicas, à preços correntes, em R\$ milhão e percentual, no estado de Rondônia, 2018 .

\begin{tabular}{|c|c|c|c|c|c|c|c|c|c|}
\hline & \multirow{2}{*}{ Atividades econômicas } & \multicolumn{2}{|c|}{ Consumo intermediário } & \multicolumn{2}{|c|}{ Demanda Final } & \multicolumn{2}{|c|}{ Demanda total } & \multicolumn{2}{|c|}{ Importações } \\
\hline & & $\mathrm{R} \$$ & $\%$ & $\mathrm{R} \$$ & $\%$ & $\mathrm{R} \$$ & $\%$ & $\mathrm{R} \$$ & $\%$ \\
\hline & Agropecuária & $\mathbf{2 . 4 5 3 , 5 7}$ & 8,05 & $2.188,69$ & 4,29 & $4.642,26$ & 5,70 & 78,31 & 1,60 \\
\hline 1 & Agricultura, inclusive o apoio à agricultura e a pós-colheita & 732,52 & 2,40 & $1.684,62$ & 3,30 & $2.417,14$ & 2,97 & 60,14 & 1,23 \\
\hline 2 & Pecuária, inclusive o apoio à pecuária & $1.540,83$ & 5,06 & 297,46 & 0,58 & $1.838,29$ & 2,26 & 1,42 & 0,03 \\
\hline \multirow[t]{2}{*}{3} & Produção florestal; pesca e aquicultura & 180,22 & 0,59 & 206,61 & 0,41 & 386,83 & 0,47 & 16,75 & 0,34 \\
\hline & Indústria & $17.712,64$ & 58,15 & $23.901,90$ & 46,86 & $41.614,53$ & 51,08 & $3.700,54$ & 75,49 \\
\hline 4 & Indústrias extrativas & 400,98 & 1,32 & $1.157,45$ & 2,27 & $1.558,43$ & 1,91 & 237,85 & 4,85 \\
\hline 5 & Indústrias de transformação & $9.922,74$ & 32,57 & $18.668,59$ & 36,60 & $28.591,34$ & 35,09 & $3.424,61$ & 69,86 \\
\hline 6 & $\begin{array}{l}\text { Eletricidade e gás, água, esgoto, atividades de gestão de resíduos e } \\
\text { descontaminação }\end{array}$ & $5.428,48$ & 17,82 & $1.022,78$ & 2,01 & $6.451,25$ & 7,92 & 26,19 & 0,53 \\
\hline \multirow[t]{2}{*}{7} & Construção & $1.960,43$ & 6,44 & $3.053,08$ & 5,99 & $5.013,51$ & 6,15 & 11,89 & 0,24 \\
\hline & Serviços & $10.296,14$ & 33,80 & $24.918,31$ & 48,85 & $35.214,45$ & 43,22 & $1.122,93$ & 22,91 \\
\hline 8 & Comércio; reparação de veículos automotores e motocicletas & $2.920,92$ & 9,59 & 383,33 & 0,75 & $3.304,26$ & 4,06 & 10,67 & 0,22 \\
\hline 9 & Transporte, armazenagem e correio & $1.775,08$ & 5,83 & $1.150,02$ & 2,25 & $2.925,11$ & 3,59 & 95,45 & 1,95 \\
\hline 10 & Alojamento e alimentação & 290,02 & 0,95 & $1.906,31$ & 3,74 & $2.196,32$ & 2,70 & 183,52 & 3,74 \\
\hline 11 & Informação e comunicação & 523,83 & 1,72 & $1.548,79$ & 3,04 & $2.072,62$ & 2,54 & 109,80 & 2,24 \\
\hline 12 & Atividades financeiras, de seguros e serviços relacionados & 671,93 & 2,21 & $2.188,35$ & 4,29 & $2.860,28$ & 3,51 & 133,65 & 2,73 \\
\hline 13 & Atividades imobiliárias & 291,99 & 0,96 & $3.717,30$ & 7,29 & $4.009,29$ & 4,92 & 28,59 & 0,58 \\
\hline 14 & $\begin{array}{l}\text { Atividades profissionais, científicas e técnicas, administrativas e } \\
\text { serviços complementares }\end{array}$ & 490,18 & 1,61 & $1.169,63$ & 2,29 & $1.659,81$ & 2,04 & 524,28 & 10,70 \\
\hline 15 & Administração, defesa, educação e saúde públicas e seguridade social & $2.351,12$ & 7,72 & $8.531,19$ & 16,72 & $10.882,31$ & 13,36 & 0,00 & 0,00 \\
\hline 16 & Educação e saúde privadas & 594,80 & 1,95 & $2.625,17$ & 5,15 & $3.219,98$ & 3,95 & 10,51 & 0,21 \\
\hline 17 & Artes, cultura, esporte e recreação e outras atividades de serviços & 386,26 & 1,27 & $1.223,60$ & 2,40 & $1.609,86$ & 1,98 & 26,46 & 0,54 \\
\hline \multirow[t]{2}{*}{18} & Serviços domésticos & 0,00 & 0,00 & 474,61 & 0,93 & 474,61 & 0,58 & 0,00 & 0,00 \\
\hline & Total & $30.462,34$ & 100 & $\mathbf{5 1 . 0 0 8 , 8 9}$ & 100 & $81.471,24$ & 100 & $4.901,78$ & 100 \\
\hline
\end{tabular}

Fonte: Autores, com dados da pesquisa. 
As atividades econômicas ligadas a Agropecuária, possuem a menor participação na demanda intermediária, total e final, bem como nas importações (Tabela 3). Dentro da Agropecuária, a Pecuária detém uma participação acima de $62 \%$ no consumo intermediário, sendo o sétimo maior contribuidor, e quase $40 \%$ na demanda final. Em Importações a Agricultura detém $77 \%$ de participação.

No setor de serviços o Comércio tem a maior participação na demanda intermediária, 28\%, seguido pela Administração Pública com quase 23\%. Esta última destaca-se, tanto na demanda final quanto na demanda total, respectivamente $34 \%$ e $31 \%$ (Tabela 3). No setor de serviços a maior participação nas importações está com as Atividades profissionais, científicas e técnicas, administrativas e serviços complementares, demandando $47 \%$ dos valores totais para o setor.

\subsection{Efeito transbordamento}

Rondônia possui maior demanda por produtos e serviços oriundos de São Paulo, com consumo intermediário estimado de 27\% (Tabela 4). Além disso, as estimativas apontam que é São Paulo quem mais demanda produtos e serviços de Rondônia (Tabela 5).

Tabela 4 - Estimativa da demanda intermediária rondoniense por produtos de outros estados, em percentual e R \$ milhão, à preços correntes, 2018.

\begin{tabular}{|c|c|c|c|c|c|c|c|c|}
\hline Acre & Amazonas & Roraima & Pará & Amapá & Tocantins & Maranhão & Piauí & Ceará \\
\hline $0,22 \%$ & $2,24 \%$ & $0,19 \%$ & $2,96 \%$ & $0,23 \%$ & $0,65 \%$ & $1,61 \%$ & $0,78 \%$ & $2,28 \%$ \\
\hline 47,15 & 486,78 & 41,53 & 643,65 & 49,97 & 140,99 & 349,99 & 169,13 & 496,04 \\
\hline $\begin{array}{c}\text { Rio Grande do } \\
\text { Norte }\end{array}$ & Paraíba & Pernambuco & Alagoas & Sergipe & Bahia & Minas Gerais & Espírito Santo & Rio de Janeiro \\
\hline $1,01 \%$ & $0,92 \%$ & $2,91 \%$ & $0,75 \%$ & $0,70 \%$ & $4,77 \%$ & $9,46 \%$ & $1,88 \%$ & $9,07 \%$ \\
\hline 220,51 & 201,17 & 632,29 & 162,55 & 151,66 & $1.037,91$ & $2.057,71$ & 410,07 & $1.973,30$ \\
\hline São Paulo & Paraíba & Santa Catarina & $\begin{array}{c}\text { Rio Grande do } \\
\text { Sul }\end{array}$ & Mato Grosso do Sul & Mato Grosso & Goiás & Distrito Federal & TOTAL \\
\hline $26,81 \%$ & $7,85 \%$ & $4,58 \%$ & $7,14 \%$ & $2,10 \%$ & $2,93 \%$ & $3,53 \%$ & $2,45 \%$ & $100 \%$ \\
\hline $5.834,33$ & $1.707,09$ & 996,95 & $1.553,42$ & 457,35 & 637,17 & 767,06 & 532,64 & $21.758,41$ \\
\hline
\end{tabular}

Fonte: Autores, com dados da pesquisa.

Tabela 5 - Estimativa da demanda intermediária de outros estados por produtos rondonienses, em percentual e R\$ milhão, à preços correntes, 2018.

\begin{tabular}{|c|c|c|c|c|c|c|c|c|}
\hline Acre & Amazonas & Roraima & Pará & Amapá & Tocantins & Maranhão & Piauí & Ceará \\
\hline $0,20 \%$ & $1,71 \%$ & $0,18 \%$ & $2,31 \%$ & $0,15 \%$ & $0,66 \%$ & $1,27 \%$ & $0,77 \%$ & $2,07 \%$ \\
\hline 49,59 & 428,8 & 45,49 & 578,55 & 36,55 & 165,06 & 317,65 & 192,65 & 518,82 \\
\hline Rio Grande do Norte & Paraíba & Pernambuco & Alagoas & Sergipe & Bahia & Minas Gerais & $\begin{array}{c}\text { Espírito } \\
\text { Santo }\end{array}$ & Rio de Janeiro \\
\hline $0,87 \%$ & $0,81 \%$ & $2,70 \%$ & $0,68 \%$ & $0,61 \%$ & $5,00 \%$ & $8,35 \%$ & $1,55 \%$ & $8,94 \%$ \\
\hline 217,6 & 202,64 & 677,18 & 171,18 & 154,18 & $1.253,37$ & $2.094,93$ & 388,7 & $2.243,00$ \\
\hline São Paulo & Santa Catarina & $\begin{array}{c}\text { Rio Grande do } \\
\text { Sul }\end{array}$ & Mato Grosso do Sul & Mato Grosso & Goiás & Distrito Federal & TOTAL & \\
\hline $41,18 \%$ & $2,32 \%$ & $6,95 \%$ & $1,28 \%$ & $2,77 \%$ & $3,96 \%$ & $2,74 \%$ & $100 \%$ & \\
\hline $10.330,94$ & 581,74 & $1.743,07$ & 319,91 & 695,19 & 993,72 & 687,32 & $25.087,82$ & \\
\hline
\end{tabular}

Fonte: Autores, com dados da pesquisa. 


\subsection{Multiplicadores de impactos econômicos e índices de ligação}

Nas relações intrarregionais de Rondônia, verifica-se que o setor de Informação e comunicação, Indústrias de transformação e Alojamento e alimentação, possuem os maiores índices. O menor multiplicador está no setor 18, Serviços domésticos, seguido de Atividades imobiliárias (Tabela 6). Para o restante do Brasil, destacam-se os setores Indústrias de Transformação, Transporte, armazenagem e correio e Pecuária.

Tabela 6 - Multiplicadores setoriais intrarregionais e inter-regionais para a estrutura produtiva de 2018.

\begin{tabular}{|c|c|c|c|c|c|}
\hline Região & Descrição das atividades & $\begin{array}{l}\text { Rondônia } \\
\text { (RO) }\end{array}$ & Ordem & $\begin{array}{c}\text { Restante } \\
\text { do Brasil } \\
\text { (RB) }\end{array}$ & Ordem \\
\hline \multirow{18}{*}{ RO } & Agricultura, inclusive apoio à agricultura e a pós-colheita & 1,083 & $11^{\circ}$ & 1,001 & $14^{\circ}$ \\
\hline & Pecuária, inclusive apoio à Pecuária & 1,012 & $15^{\circ}$ & 1,009 & $1^{\mathrm{o}}$ \\
\hline & Produção florestal, pesca e aquicultura & 1,032 & $13^{\circ}$ & 1,008 & $3^{\circ}$ \\
\hline & Indústrias extrativas & 1,339 & $5^{\circ}$ & 1,007 & $4^{\circ}$ \\
\hline & Indústrias de transformação & 1,689 & $2^{\circ}$ & 0,999 & $18^{\circ}$ \\
\hline & Eletricidade e gás, água, esgoto, atividades de gestão de resíduos e descontaminação & 1,054 & $12^{\circ}$ & 1,006 & $5^{\circ}$ \\
\hline & Construção & 1,108 & $9^{\circ}$ & 1,004 & $9^{\circ}$ \\
\hline & Comércio e reparação de veículos automotores e motocicletas & 1,027 & $14^{\circ}$ & 1,000 & $16^{\circ}$ \\
\hline & Transporte, armazenagem e correio & 1,144 & $7^{\circ}$ & 1,001 & $13^{\circ}$ \\
\hline & Alojamento e alimentação & 1,398 & $3^{\circ}$ & 1,004 & $7^{\circ}$ \\
\hline & Informação e comunicação & 1,774 & $1^{\mathrm{o}}$ & 1,002 & $10^{\circ}$ \\
\hline & Atividades financeiras, de seguros e serviços relacionados & 1,395 & $4^{\circ}$ & 1,001 & $15^{\circ}$ \\
\hline & Atividades imobiliárias & 1,005 & $17^{\circ}$ & 1,005 & $6^{\circ}$ \\
\hline & Atividades profissionais, científicas e técnicas, administrativas e serviços complementares & 1,314 & $6^{\circ}$ & 1,004 & $8^{\circ}$ \\
\hline & Administração, defesa, educação e saúde públicas e seguridade social & 1,010 & $16^{\circ}$ & 1,001 & $12^{\circ}$ \\
\hline & Educação e saúde privadas & 1,087 & $10^{\circ}$ & 1,002 & $11^{\circ}$ \\
\hline & Artes, cultura, esporte e recreação e outras atividades de serviços & 1,137 & $8^{\circ}$ & 1,008 & $2^{\circ}$ \\
\hline & Serviços domésticos & 1,000 & $18^{\circ}$ & 1,000 & $17^{\circ}$ \\
\hline \multirow{18}{*}{$\mathrm{RB}$} & Agricultura, inclusive apoio à agricultura e a pós-colheita & 1,455 & $8^{\circ}$ & 1,962 & $9^{\circ}$ \\
\hline & Pecuária, inclusive apoio à Pecuária & 1,414 & $9^{\circ}$ & 2,281 & $3^{\circ}$ \\
\hline & Produção florestal, pesca e aquicultura & 1,314 & $11^{\circ}$ & 1,971 & $8^{\circ}$ \\
\hline & Indústrias extrativas & 1,991 & $3^{\circ}$ & 2,107 & $5^{\circ}$ \\
\hline & Indústrias de transformação & 1,607 & $5^{\circ}$ & 5,338 & $1^{\circ}$ \\
\hline & Eletricidade e gás, água, esgoto, atividades de gestão de resíduos e descontaminação & 1,830 & $4^{\circ}$ & 2,073 & $6^{\circ}$ \\
\hline & Construção & 1,998 & $2^{\circ}$ & 2,245 & $4^{\circ}$ \\
\hline & Comércio e reparação de veículos automotores e motocicletas & 1,508 & $7^{\circ}$ & 1,839 & $11^{\circ}$ \\
\hline & Transporte, armazenagem e correio & 2,676 & $1^{\mathrm{o}}$ & 2,335 & $2^{\circ}$ \\
\hline & Alojamento e alimentação & 1,002 & $17^{\circ}$ & 2,053 & $7^{\circ}$ \\
\hline & Informação e comunicação & 1,191 & $13^{\circ}$ & 1,934 & $10^{\circ}$ \\
\hline & Atividades financeiras, de seguros e serviços relacionados & 1,073 & $14^{\circ}$ & 1,443 & $15^{\circ}$ \\
\hline & Atividades imobiliárias & 1,061 & $16^{\circ}$ & 1,083 & $17^{\circ}$ \\
\hline & Atividades profissionais, científicas e técnicas, administrativas e serviços complementares & 1,072 & $15^{\circ}$ & 1,578 & $14^{\mathrm{o}}$ \\
\hline & Administração, defesa, educação e saúde públicas e seguridade social & 1,206 & $12^{\circ}$ & 1,417 & $16^{\circ}$ \\
\hline & Educação e saúde privadas & 1,405 & $10^{\circ}$ & 1,620 & $13^{\circ}$ \\
\hline & Artes, cultura, esporte e recreação e outras atividades de serviços & 1,586 & $6^{\circ}$ & 1,719 & $12^{\circ}$ \\
\hline & Serviços domésticos & 1,000 & $18^{\circ}$ & 1,000 & $18^{\circ}$ \\
\hline
\end{tabular}

Fonte: Autores, com dados da pesquisa.

Nas relações inter-regionais de Rondônia, destacam-se o setor de Transporte, armazenagem e correios, seguido de Construção e Indústrias extrativas (Tabela 6). Os menores estão nos setores de Alojamento e alimentação e Serviços domésticos. Para o restante do Brasil, destacam-se os setores Pecuária, Artes, cultura, esporte e recreação e outras atividades de serviços e Produção florestal, pesca e aquicultura.

Os índices de ligações apontam que as relações intrarregionais rondonienses apresentam maiores relações de dependência tanto para trás quanto para frente nos setores Informação e comunicação, Indústrias de transformação e Alojamento e alimentação (Tabela 7). Suas relações com outros estados evidencia uma maior dependência nos setores 
Transporte, armazenagem e correios, Construção e Indústrias extrativas. $O$ índice de ligação para frente apresenta como destaque Transporte, armazenagem e correios, Construção e Atividades imobiliárias.

Nas relações do restante do Brasil com Rondônia, há maior dependência nos setores Pecuária, Artes, cultura, esporte e recreação e outras atividades de serviços e Produção florestal, pesca e aquicultura. Para frente, os setores de Construção, Atividades imobiliárias e Artes, cultura, esporte e recreação e outras atividades de serviços, destacam-se.

Tabela 7 - Índices de ligações para trás (ILT) e para frente (ILF), intrarregionais e inter-regionais para a estrutura produtiva de 2018.

\begin{tabular}{|c|c|c|c|c|c|c|c|c|c|}
\hline \multirow[b]{2}{*}{ Região } & \multirow[b]{2}{*}{ Descrição das atividades } & \multicolumn{4}{|c|}{ Rondônia (RO) } & \multicolumn{4}{|c|}{ Restante do Brasil (RB) } \\
\hline & & ILT & Ordem & ILF & Ordem & ILT & Ordem & ILF & Ordem \\
\hline \multirow{18}{*}{ RO } & Agricultura, inclusive apoio à agricultura e a pós-colheita & 0,902 & $11^{\circ}$ & 0,892 & $11^{\circ}$ & 0,998 & $14^{\circ}$ & 1,003 & $4^{\circ}$ \\
\hline & Pecuária, inclusive apoio à Pecuária & 0,843 & $15^{\circ}$ & 0,852 & $16^{\circ}$ & 1,006 & $1^{\circ}$ & 0,998 & $12^{\circ}$ \\
\hline & Produção florestal, pesca e aquicultura & 0,860 & $13^{\circ}$ & 0,861 & $15^{\circ}$ & 1,004 & $3^{\circ}$ & 0,997 & $15^{\circ}$ \\
\hline & Indústrias extrativas & 1,115 & $5^{\circ}$ & 1,065 & $6^{\circ}$ & 1,004 & $4^{\circ}$ & 0,998 & $11^{\circ}$ \\
\hline & Indústrias de transformação & 1,407 & $2^{\circ}$ & 1,417 & $2^{\circ}$ & 0,996 & $18^{\circ}$ & 1,002 & $5^{\circ}$ \\
\hline & Eletricidade e gás, água, esgoto, atividades de gestão de resíduos e descontaminação & 0,878 & $12^{\circ}$ & 0,878 & $12^{\circ}$ & 1,002 & $5^{\circ}$ & 0,999 & $7^{\circ}$ \\
\hline & Construção & 0,923 & $9^{\circ}$ & 0,954 & $7^{\circ}$ & 1,000 & $9^{\circ}$ & 1,009 & $1^{\circ}$ \\
\hline & Comércio e reparação de veículos automotores e motocicletas & 0,855 & $14^{\circ}$ & 0,870 & $14^{\circ}$ & 0,997 & $16^{\circ}$ & 0,998 & $13^{\circ}$ \\
\hline & Transporte, armazenagem e correio & 0,953 & $7^{\circ}$ & 0,949 & $8^{\circ}$ & 0,998 & $13^{\circ}$ & 0,999 & $9^{\circ}$ \\
\hline & Alojamento e alimentação & 1,165 & $3^{\circ}$ & 1,160 & $3^{\circ}$ & 1,001 & $7^{\circ}$ & 1,001 & $6^{\circ}$ \\
\hline & Informação e comunicação & 1,478 & $1^{\circ}$ & 1,456 & $1^{\circ}$ & 0,998 & $10^{\circ}$ & 0,998 & $14^{\circ}$ \\
\hline & Atividades financeiras, de seguros e serviços relacionados & 1,162 & $4^{\circ}$ & 1,146 & $4^{\circ}$ & 0,997 & $15^{\circ}$ & 0,997 & $16^{\circ}$ \\
\hline & Atividades imobiliárias . & 0,837 & $17^{\circ}$ & 0,876 & $13^{\circ}$ & 1,001 & $6^{\circ}$ & 1,007 & $2^{\circ}$ \\
\hline & $\begin{array}{l}\text { Atividades profissionais, científicas e técnicas, administrativas e serviços } \\
\text { complementares }\end{array}$ & 1,095 & $6^{\circ}$ & 1,099 & $5^{\circ}$ & 1,000 & $8^{\circ}$ & 0,999 & $8^{\circ}$ \\
\hline & Administração, defesa, educação e saúde públicas e seguridade social & 0,842 & $16^{\circ}$ & 0,841 & $17^{\circ}$ & 0,998 & $12^{\circ}$ & 0,997 & $17^{\circ}$ \\
\hline & Educação e saúde privadas & 0,905 & $10^{\circ}$ & 0,905 & $10^{\circ}$ & 0,998 & $11^{\circ}$ & 0,998 & $10^{\circ}$ \\
\hline & Artes, cultura, esporte e recreação e outras atividades de serviços & 0,947 & $8^{\circ}$ & 0,946 & $9^{\circ}$ & 1,004 & $2^{\circ}$ & 1,004 & $3^{\circ}$ \\
\hline & Serviços domésticos & 0,833 & $18^{\circ}$ & 0,833 & $18^{\circ}$ & 0,997 & $17^{\circ}$ & 0,997 & $18^{\circ}$ \\
\hline \multirow{18}{*}{$\mathrm{RB}$} & Agricultura, inclusive apoio à agricultura e a pós-colheita & 0,992 & $8^{\circ}$ & 0,999 & $6^{\circ}$ & 0,981 & $9^{\circ}$ & 1,049 & $5^{\circ}$ \\
\hline & Pecuária, inclusive apoio à Pecuária & 0,964 & $9^{\circ}$ & 0,846 & $11^{\circ}$ & 1,141 & $3^{\circ}$ & 0,802 & $11^{\circ}$ \\
\hline & Produção florestal, pesca e aquicultura & 0,896 & $11^{\circ}$ & 0,902 & $9^{\circ}$ & 0,985 & $8^{\circ}$ & 0,532 & $15^{\circ}$ \\
\hline & Indústrias extrativas & 1,358 & $3^{\circ}$ & 0,753 & $12^{\circ}$ & 1,053 & $5^{\circ}$ & 0,220 & $17^{\circ}$ \\
\hline & Indústrias de transformação & 1,096 & $5^{\circ}$ & 1,450 & $4^{\circ}$ & 2,669 & $1^{\circ}$ & 3,674 & $1^{\circ}$ \\
\hline & Eletricidade e gás, água, esgoto, atividades de gestão de resíduos e descontaminação & 1,248 & $4^{\circ}$ & 0,932 & $8^{\circ}$ & 1,037 & $6^{\circ}$ & 0,902 & $8^{\circ}$ \\
\hline & Construção & 1,363 & $2^{\circ}$ & 2,046 & $2^{\circ}$ & 1,123 & $4^{\circ}$ & 2,268 & $2^{\circ}$ \\
\hline & Comércio e reparação de veículos automotores e motocicletas & 1,029 & $7^{\circ}$ & 0,899 & $10^{\circ}$ & 0,920 & $11^{\circ}$ & 0,983 & $7^{\circ}$ \\
\hline & Transporte, armazenagem e correio & 1,826 & $1^{\circ}$ & 2,355 & $1^{\circ}$ & 1,168 & $2^{\circ}$ & 1,377 & $3^{\circ}$ \\
\hline & Alojamento e alimentação & 0,683 & $17^{\circ}$ & 0,693 & $14^{\circ}$ & 1,026 & $7^{\circ}$ & 1,019 & $6^{\circ}$ \\
\hline & Informação e comunicação & 0,812 & $13^{\circ}$ & 0,746 & $13^{\circ}$ & 0,967 & $10^{\circ}$ & 0,630 & $12^{\circ}$ \\
\hline & Atividades financeiras, de seguros e serviços relacionados & 0,732 & $14^{\circ}$ & 0,685 & $15^{\circ}$ & 0,722 & $15^{\circ}$ & 0,612 & $13^{\circ}$ \\
\hline & Atividades imobiliárias & 0,724 & $16^{\circ}$ & 1,677 & $3^{\circ}$ & 0,541 & $17^{\circ}$ & 1,088 & $4^{\circ}$ \\
\hline & $\begin{array}{l}\text { Atividades profissionais, científicas e técnicas, administrativas e serviços } \\
\text { complementares }\end{array}$ & 0,731 & $15^{\circ}$ & 0,000 & $18^{\circ}$ & 0,789 & $14^{\circ}$ & 0,108 & $18^{\circ}$ \\
\hline & Administração, defesa, educação e saúde públicas e seguridade social & 0,822 & $12^{\circ}$ & 0,682 & $16^{\circ}$ & 0,709 & $16^{\circ}$ & 0,572 & $14^{\circ}$ \\
\hline & Educação e saúde privadas & 0,958 & $10^{\circ}$ & 0,962 & $7^{\circ}$ & 0,810 & $13^{\circ}$ & 0,810 & $10^{\circ}$ \\
\hline & Artes, cultura, esporte e recreação e outras atividades de serviços & 1,082 & $6^{\circ}$ & 1,078 & $5^{\circ}$ & 0,859 & $12^{\circ}$ & 0,855 & $9^{\circ}$ \\
\hline & Serviços domésticos & 0,682 & $18^{\circ}$ & 0,682 & $17^{\circ}$ & 0,500 & $18^{\circ}$ & 0,500 & $16^{\circ}$ \\
\hline
\end{tabular}

Fonte: Autores, com dados da pesquisa.

\section{Discussão}

Uma análise setorial abrangente mostra que o Estado de Rondônia possui forte destaque na Indústria e nos Serviços, no entanto, com fraca participação setorial da Agropecuária (Figura 1). Entretanto, uma análise mais atenta permite identificar uma relativa contribuição da pecuária para a economia local, cuja importância se destaca ao analisar as relações dos outros estados com Rondônia. 
Os multiplicadores de produção demonstram que os setores Informação e comunicação, Indústrias de transformação e Alojamento e alimentação, possuem a maior capacidade de respostas a alterações incrementais na produção destes setores. Assim, tomando-se Indústrias de transformações, por exemplo, há um indicativo de que investimentos que estimulem esse setor terão uma resposta de 1,7 vezes o valor nele investido. Isso demonstra a importância que o setor desempenha na estrutura econômica do estado, tornando-o altamente atrativo para futuras ações incrementais no setor. O setor de Alojamento e alimentação, que também apresenta uma boa capacidade de resposta $(1,4)$ parece ser de grande relevância para o desenvolvimento de uma melhor estrutura de serviços, uma vez que serviços de alimentação tendem a atender uma razoável parcela de pequenas e microempresas. Importante ressaltar que todos os setores apresentaram multiplicador maior ou igual a um, indicando sua importância relativa.

A análise a partir dos índices de ligação mostram que seis setores intrarregionais de Rondônia estão acima da média, uma vez que apresentaram índice maior ou igual a um, sendo, portanto, os que demonstram uma maior importância estrutural. Os altos índices de ligação para trás observados nestas relações, como é o caso do setor de Indústrias de transformação, indicam que a cada acréscimo de investimento neste setor, aqueles que são por estes demandados sofrerão impactos diretos e indiretos, aumentando, por sua vez, a sua produção para atender a demanda do primeiro. Maiores informações são necessárias, mas é de se supor que, um incremento em Indústrias de transformações poderá levar a um incremento também no setor de Indústrias extrativas, uma vez que este é tradicionalmente um fornecedor de insumos para a indústria. No caso rondoniense, onde parte do setor de transformação está ligado a área de alimentos, espera-se um impacto nos setores agropecuários. Ressalta-se, que seria interessante um aprofundamento do porquê tais setores aparecem em destaque quando se olha a economia do Estado a partir de uma visão mais ampla, de forma a identificar causalidades e correlações. Por exemplo, poderia o setor de Transporte, armazenagem e correio, que também aparece em destaque, e com uma capacidade de resposta maior que dois e meio, estar respondendo a um aumento da demanda de consumo por produtos via e-commerce? Os índices de ligações para frente intrarregionais do estado apresentam comportamento similar, demonstrando que os mesmos setores possuem relevância quanto ao seu encadeamento dos setores anteriores e sua dependência quanto aos demais.

Nas compras do resto do Brasil em relação à Rondônia, os setores de Pecuária e Produção Florestal (que inclui pesca e aquicultura) aparecem em destaque, indicando a importância dos produtos desses setores com encadeamento para trás. Aliás, importante considerar o fato de que Rondônia tem sua história ligada ao desenvolvimento do setor agropecuário, baseado em grandes propriedades. Inclusive, é uma diretriz do plano de desenvolvimento estadual para o período de 2015-2030 "continuar investindo em aumento de produtividade" na agropecuária (Rondônia, 2015).

Construção e Atividades imobiliárias destacam-se quando se trata de encadeamento para frente. Há aqui, uma ideia intuitiva do porquê estes dois setores aparecem em conjunto, uma vez que um pode ser considerado insumo do outro. Estes setores também estão em destaque nas relações de compras do Resto do Brasil com os demais estados, mostrando que sua importância é também relevante à nível nacional.

As teorias de desenvolvimento que enfatizam o local, o regional e o endógeno destacam a utilização do capital local para alimentação e estímulo das atividades econômicas do local, de forma a valorizar o que é oferecido em termos de recursos (natural, humano) em uma forma de desenvolvimento que repercuta tais possibilidades (Amaral Filho, 1996; Arend, Cario, \& Enderle, 2012). Isso evitaria a implementação de um modelo "estrangeiro" que não reflete o local e que poderia trazer mais prejuízos que benefícios. A MIP-RO vista sob essa perspectiva apresenta a possibilidade de um planejamento econômico e social com base nos principais setores da economia, uma vez que seus impactos tendem a repercutir no restante da estrutura econômica. Além disso, acredita-se em uma visão onde a participação do Estado é fundamental, de forma a estimular e direcionar setores que poderão gerar emprego e renda, no entanto, combinada com a atuação de instituições locais robustas (MULS, 2008), subsidiadas por informações econômicas sólidas, como as obtidas pela MIP-RO. 
Conforme a decisão que os tomadores de políticas econômicas se submetam, se estimular a economia internamente ou suas relações com outros estados, os resultados apresentados podem indicar um caminho a seguir. No primeiro caso, percebese que estímulos aos setores Informação e comunicação, Indústrias de transformação e Alojamento e alimentação poderiam cooperar com o desenvolvimento da região.

No segundo caso, os setores Pecuária e Produção florestal, pesca e aquicultura, poderiam desempenhar papel importante uma vez que recebessem estímulos para tal aumentando sua produção para exportação. Por outro lado, deve-se considerar que o modelo atual (produção extensiva e exportação) adotado nestes setores, tem sido alvo de críticas devido as externalidades ambientais e sociais (Campos \& Higuchi, 2009; Nobre, et al., 2016; Marques, 2016).

Dessa forma, acredita-se que uma política pública com investimentos voltados para os setores em destaque pode ser viável, no entanto, considerando o histórico local, sugere-se que tais medidas sejam acopladas com ações sustentáveis, de preservação e conservação da floresta amazônica, onde Rondônia se insere. Dito de outra forma, uma política alinhada com uma concepção mais abrangente de desenvolvimento sustentável que busque mitigar os atuais impactos negativos do modelo atual de uso e ocupação do espaço, bem como utilizar de forma mais apropriada os recursos naturais disponíveis, em conformidade com a ideia de "Uma terceira via como paradigma de desenvolvimento sustentável" (Nobre, et al., 2016; Nobre, 2018; Nobre \& Nobre, 2018).

\section{Conclusão}

Os resultados apresentados demonstram que a metodologia apresentada é suficiente para a construção da Matriz Insumo-Produto para Rondônia (MIP-RO), possibilitando a estimação das relações intersetoriais e suas interdependências, bem como alguns indicadores importantes para a compreensão mais aprofundada da economia estadual.

A análise com base nos indicadores demonstra a importância dos setores Informação e comunicação, Indústrias de transformação e Alojamento e alimentação para as relações internas à economia do Estado. Construção e Transporte, armazenagem e correio e Indústrias extrativas aparecem como fonte importante das relações econômicas de Rondônia com os outros estados. Tais resultados sugerem que há espaço para estímulo da economia local, de forma a melhorar os retornos econômicos e sociais a partir dos setores escolhidos. A Pecuária também se mostra de grande importância quando se olha da perspectiva dos outros Estados demandando de Rondônia.

Uma análise multissetorial é clara em apontar os setores que devem ser valorizados pelos tomadores de decisão, no entanto, não há impedimentos no que se refere a sua adequação aos objetivos de desenvolvimento escolhidos para a região. Como a MIP possui aspecto prospectivo, espera-se que possa contribuir para o planejamento econômico e desenvolvimento de Rondônia e demais estados da Amazônia.

Assim, novas pesquisas poderão ser realizadas de forma a analisar por que a estrutura econômica de Rondônia está disposta como apresentada, que políticas públicas levaram a essa configuração. Análise de cenários são também importantes para verificar impactos na estrutura de forma a melhor compreender as inter-relações existentes entre os setores.

\section{Referências}

Amaral Filho, J. d. (Dez de 1996). Desenvolvimento regional endógeno em um ambiente federalista. Planejamento e políticas públicas - IPEA, 14, 35-74.

Arend, M., Cario, S. A., \& Enderle, R. A. (2012). Instituições, inovações e desenvolvimento econômico. Pesquisa \& Debate, 1(41), 110-133.

Becker, B. K. (2005). Geopolítica da Amazônia. Estudos Avançados, 19(53), 71-86.

Calatrava-Requena, J. (2016). Origin and evolution of Rural Development concept and policies: From rural communities to territories. V Encontro Rural RePort and the XV Congreso de Historia Agraria de la SEHA. University Institute of Lisbon.

Campos, M. T., \& Higuchi, F. G. (2009). A floresta Amazônica e seu papel nas mudanças climáticas. SDS/CECLIMA. 
Chen, Q., Zhu, K., Liu, P., Chen, X., Tian, K., Yang, L., \& Yang, C. (2018). Distinguishing China's processing trade in the world input-output table and quantifying its effects. Economic Systems Research.

Fearnside, P. M. (1997). Limiting factors for development of agriculture and ranching in Brazilian Amazonia. Revista Brasileira de Biologia, 57(4), 531-549.

Fearnside, P. M. (June de 2005). Deforestation in Brazilian Amazonia: History, Rates, and Consequences. Conservation Biology, 19(3), 680-688.

Finamore, E. B. (2018). As contas nacionais e os multiplicadores de impacto de insumo-produto: mensurando o desenvolvimento brasileiro. Appris.

Guilhoto, J. J., \& Sesso-Filho, U. A. (abr-jun de 2005). Estimação da Matriz Insumo-Produto a partir de dados preliminares das Contas Nacionais. Economia Aplicada.

Guilhoto, J. J., Gonçalves Junior, C. A., Visentin, J. C., Imori, D., \& Ussami, K. A. (2017). Construção da Matriz Inter-Regional de Insumo-Produto para o Brasil: uma aplicação do TUPI.

Günther, J., Kristalova, M., \& Ludwig, U. (2019). Structural stability of the research \& development sector in European economies despite the economic crisis. Journal of Evolutionary Economics. https://doi.org/10.1007/s00191-019-00640-z

Haddad, P. R. (1976). Contabilidade social e economia regional: análise de insumo-produto. Zahar Editores.

IBGE. (2010). IBGE Cidades - Censo de 2010. IBGE.

IBGE. (2018). Contas Regionais 2016: entre as 27 unidades da federação, somente Roraima teve crescimento do PIB. IBGE.

IBGE. (2018). Contas Regionais do Brasil - 2018. IBGE.

IBGE. (2018). Matriz de Insumo-Produto Brasil: 2015. IBGE.

IBGE. (2019). IBGE cidades. IBGE.

INPE. (2019). Observatório da Terra. http://www.obt.inpe.br/OBT/assuntos/programas/amazonia/prodes

Isard, W. (Nov de 1951). Interregional and Regional Input-Output Analysis: A Model of a Space-Economy. The Review of Economics and Statistics, 33(4), 318-328.

Jackson, T. (2009). Prosperity without growth: economics for a finite planet. Earthscan.

Lenzen, M. (1998). Primary energy and greenhouse gases embodied in Australian final consumption: an input-output analysis. Energy Policy, 26(6), 495506.

Lenzen, M., Murray, S. A., Korte, B., \& Dey, C. J. (2003). Environmental impact assessment including indirect effects - a case study using input-output analysis. Environmental Impact Assessment Review, 23, 263-282.

Lizundia-Loiola, J., Pettinari, M. L., \& Chuvieco, E. (2020). Temporal Anomalies in Burned Area Trends: Satellite Estimations of the Amazonian 2019 Fire Crisis. Remote Sensing, 12(1).

Marques, L. (2016). Capitalismo e colapso ambiental (2a ed.). Editora da Unicamp.

Martins, G. d., \& Theóphilo, C. R. (2009). Metodologia da investigação científica para ciências sociais aplicadas (2a ed.). Atlas.

Meadows, D. H., Meadows, D. L., Randers, J., \& Behrens III, W. W. (1972). The limits to growth. A report for the Club of Rome's project on the predicament of mankind. New York: Universe Books.

Mellos, K. (1988). Theory of Eco-development. Em K. Mellos, Perspectives on Ecology, A Critical Essay, 59-74. Macmillian Press LTD. doi:10.1007/978-1$349-19598-5$

Muller, R. E., \& Blair, P. D. (2009). Input-output analysis - foundations and extensions (2 ed.). Cambridge University Press.

MULS, L. M. (Janeiro/Abril de 2008). Desenvolvimento local, espaço e território: o conceito de capital social e a importância da formação de redes entre organismos e instituições locais. Revista Economia.

Nobre, C. A. (2018). The Amazon Third Way Initiative/Amazonia 4.0: Radically changing the sustainable development paradigm for the Amazon. (U. M. Oficina Regional de Ciencias de la UNESCO para América Latina y el Caribe, Ed.) París: Organización de las Naciones Unidas para la Educación, la Ciencia y la Cultura.

Nobre, C. A., Sampaio, G., Borma, L. S., Castilla-Rubio, J. C., Silva, J. S., \& Cardoso, M. (September de 2016). Land-use and climate change risks in the Amazon and the need of a novel sustainable development paradigm. PNAS, 113(39), 10759-10768.

Nobre, I., \& Nobre, C. A. (2018). The Amazonia Third Way Initiative: The Role of Technology to Unveil the Potential of a Novel Tropical Biodiversity-Based Economy. Em L. Loures, Land Use - Assessing the Past, Envisioning the Future (pp. 183-2013). IntechOpen.

Paulani, L. M., \& Braga, M. B. (2007). A nova contabilidade social: uma introdução à macroeconomia (3a ed.). Saraiva.

Pereira, A. S., Shitsuka, D. M., Parreira, F. J., \& Shitsuka, R. (2018). Metodologia da pesquisa científica. UFSM. 
Research, Society and Development, v. 10, n. 4, e28310414202, 2021 (CC BY 4.0) | ISSN 2525-3409 | DOI: http://dx.doi.org/10.33448/rsd-v10i4.14202

Piontekowski, V. J., Ribeiro, F. P., Matricardi, E. A., Junior, I. M., Bussinguer, A. P., \& Gatto, A. (2019). Modeling deforestation in the state of Rondônia. Floresta e Ambiente, pp. 1-11.

Richardson, H. W. (1978). Insumo-produto e economia regional. Zahar Editores.

Rondônia, G. d. (2015). Plano de desenvolvimento estadual sustentável de Rondônia - 2015-2030. Governo de Rondônia.

Sachs, I. (2008). Caminhos para o desenvolvimento sustentável (3 ed.). Garamond.

Seers, D. (1969). The Meaning of Development. IDS Communication 44. Brighton: Institute of Development Studies.

Silveira, M., Petri, C., Broggio, I., Chagas, G., Macul, M., Leite, C., \& Aragão, L. (2020). Drivers of Fire Anomalies in the Brazilian Amazon: Lessons Learned from the 2019 Fire Crisis. Land, 9(12).

Soubbotina, T. P., \& Sheram, K. A. (2000). Beyond economic growth: meeting the challenges of global development. The World Bank.

Souza, N. d. (Março de 1997). Projeção e regionalização da matriz de insumo-produto: impacto do aumento da produção no RS e no Brasil no ano 2000. Análise Econômica, pp. 110-129.

Souza, N. d. (1999). Desenvolvimento econômico (4a ed.). Editora Atlas S.A.

Souza, N. d. (jan./jul. de 2005). Teoria dos pólos, regiões inteligentes e sistemas regionais de inovação. Análise, pp. 87-112. http://revistaseletronicas.pucrs.br/fo/ojs/index.php/face/article/view/266/215

Wang, S., Fath, B., \& Chen, B. (2019). Energy-water nexus under energy mix scenarios using input-output and ecological network analyses. Applied Energy, $233-234,826-839$.

WCED. (1987). Our Future Common Oxford University Press

Wood, R. (2009). Structural decomposition analysis of Australia's greenhouse gas emissions. Energy Policy, 37, 4943-4948. 